\title{
Implementation of guidelines to integrate the caregiver as a coassistant of health-care personnel during the hospital stay of COVID-19 pediatric patients: adaptation in a Mexican public pediatric hospital
}

\author{
Mercedes Luque-Coqui ${ }^{1}$, María J. Adame-Vivanco ${ }^{1 *}$, Daniela de la Rosa-Zamboni², \\ Patricia Mendoza-Rodríguez ${ }^{1}$, Mariana Campos-Gutiérrez ${ }^{3}$, Sofía Campos-Ugalde ${ }^{3}$, \\ María F. Busqueta-Mendoza ${ }^{4}$, Carolyn Young-Fernández ${ }^{5}$, and Francisco Morales-Carmona ${ }^{6}$ \\ ${ }^{1}$ Departamento de Psiquiatría, Hospital Infantil de México Federico Gómez; ${ }^{2}$ Departamento de Epidemiología, Hospital Infantil de México Federico \\ Gómez; ${ }^{3}$ Grupo SoHMA Acompañamiento Emocional Hospitalario; ${ }^{4}$ Centro de Estudios Psicosociales Aplicados a la Salud (CENEPAS); ${ }^{5}$ StoryBox \\ Hospitalización Infantil; ${ }^{6}$ Red Latinoamericana de Psicología Pediátrica. Mexico City, Mexico
}

\begin{abstract}
This paper describes the experience in a public pediatric hospital when implementing the Mexican Health Ministry's recommendations on the inclusion and importance of a chosen caregiver during the hospitalization of a coronavirus disease 2019 (COVID-19) pediatric patient. The implementation includes the adjustments, observations, and limitations made in real practice and process. In conclusion, the value and benefits of the accompaniment of hospitalized children with COVID-19 by a primary or chosen caregiver are evidenced and supported by family-centered care. Furthermore, the recommendations mentioned result in comprehensive bio-psycho-social care for the benefit of pediatric patients.
\end{abstract}

Key words: Pediatric psychology. Hospitalization. Coronavirus 2019. Accompaniment. Families.

Implementación de guías para integrar al cuidador como coauxiliar del equipo de salud durante la estancia hospitalaria del paciente pediátrico con COVID-19: adaptación en un hospital pediátrico público mexicano

\section{Resumen}

Se describe cómo el Hospital Infantil de México Federico Gómez pone en funcionamiento las recomendaciones publicadas por la Secretaría de Salud sobre la inclusión y la importancia del acompañamiento de un cuidador primario durante la hospitalización del paciente pediátrico con COVID-19. Se incluyen las adecuaciones, las observaciones y las limitaciones del proceso. Se concluye acerca de la importancia de la flexibilidad y el buen uso de los recursos en la implementación de la guía. Además, se examinan la atención biopsicosocial integral en beneficio de los menores y la importancia del acompañamiento, que se sustenta en la atención centrada en la familia y la integración del cuidador como auxiliar en el equipo médico.

Palabras clave: Psicología pediátrica. Hospitalización. COVID-19. Acompañamiento. Familias.

\section{Correspondence:}

*María J. Adame Vivanco

E-mail: mjadame@gmail.com

(http://creativecommons.org/licenses/by-nc-nd/4.0/)
Available online: 02-03-2021 Bol Med Hosp Infant Mex. 2021;78(2):102-109 www.bmhim.com 


\section{Introduction}

Pediatric inpatients are a vulnerable population that requires specific comprehensive treatment, distinct from adults. During the coronavirus disease 2019 (COVID-19) pandemic, about $2 \%$ of cases worldwide have been reported as pediatric patients, of which $5.9 \%$ may have complications and require hospital management ${ }^{1,2}$. Based on the literature regarding the hospitalized COVID-19 pediatric patients and the evidence reported by international Pediatric Associations and Ministries of Health2-6, the Mexican Ministry of Health (Secretaría de Salud [SS]) issued recommendations for the hospitalization of children with COVID-19, highlighting a transdisciplinary approach based on the family-centered model ${ }^{7}$. The recommendations incorporate the continuous presence of a family member as a coassistant for the patient's care to reduce healthcare personnel physical and psychological risks, the negative psychological impact on the patient and their family, and optimize the operation of the hospita| ${ }^{8,9}$. Similarly, it is based on the fact that the presence of a family member increases the cooperation of the patient, decreases the duration of hospital stay, increases the efficiency of the treatment, and decreases emotional stress and the perception of pain ${ }^{1,10}$.

International institutions emphasize that children must remain accompanied at all moments while also considering the caregiver's characteristics, such as being under 60 years of age and any comorbidities present ${ }^{6,11}$.

Regarding legal and bioethical aspects, it is an obligation to promote respect for the universal rights of children both outside and inside the hospital, to care for their biopsychosocial development, and to recognize that it is a fundamental right to remain accompanied by their caregiver, as it protects them from the possible threats and dangers associated with hospitalization ${ }^{12}$.

The following is a summary of the guideline published by the SS:

1. Patient's arrival. A medical evaluation process to confirm COVID-19 diagnosis and an optimal caregiver selection through physical health screening are carried out. In the case that the primary caregiver is not optimal, another family member is contacted.

2. Reading and signing of the agreement. The assigned staff reads and ensures that the caregiver adequately understands and signs the agreement.

3. Caregiver training. Nursing personnel trains the caregiver in biosafety, protective equipment, hand hygiene, and fundamental aspects of care, which the family member will perform during the patient's hospital stay.

4. Mental health. Mental health personnel assess the caregiver and intervene if considered appropriate (in person or remotely). If there are no psychologists in the hospital, the caregiver will be referred to the SS telephone support program. The mental health staff will provide telephone follow-up every 48-72 $\mathrm{h}$ and provide emotional support to the caregiver and the patient to prevent crises.

\section{Follow-up during the hospital stay}

\section{Monitoring of the caregiver}

The assigned staff is responsible for monitoring daily body temperature and symptoms associated with COVID-19.

\section{Information}

Medical staff must provide daily and continuous information to the caregiver to create trust and confidence. Preferably, communication should be by telephone to maintain safe distancing between staff and patient/ caregiver.

\section{Caregiver nutrition}

The hospital must provide daily meals for the caregiver so that the caregiver can remain confined. If it is not possible for the hospital to provide these resources, non-governmental organizations or volunteer groups should be contacted for help (Fig. 1).

\section{Problem statement}

Difficulties are generated by this pandemic, such as the low percentage of pediatric patients and the general lack of knowledge produced by an abrupt crisis, which caused the application of protocols developed for adults to pediatric patients over the country. These difficulties also implied the separation of children from their families during hospitalization, without considering their different needs.

For children to remain hospitalized in an unknown environment, be separated from their family, be evaluated by unknown professionals, uncertainty, and the disruption of their daily life constitute an accumulation of circumstances that generate feelings of defenselessness $^{13}$. Therefore, pediatric patients require their 


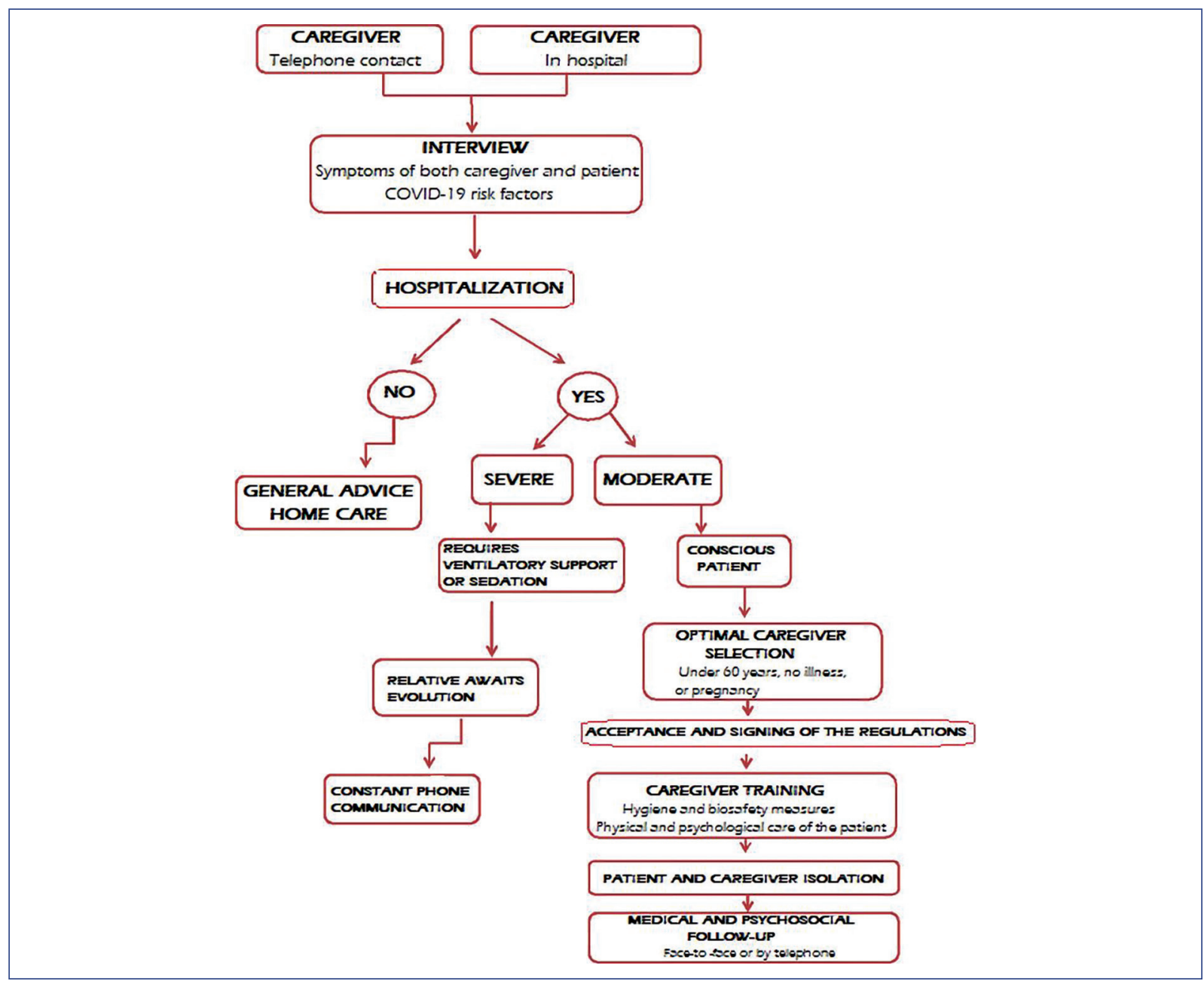

Figure 1. Flowchart published on the COVID-19 guidelines of the Ministry of Health (Secretaría de Salud, SS). COVID-19: coronavirus disease 2019.

primary sources of containment, security, and socialization to face this situation in a better capacity ${ }^{14}$. Furthermore, it is necessary to acquire strategies to overcome negative effects ${ }^{15}$. Moreover, the accompaniment can prevent psychological complications such as post-traumatic stress or acute stress reactions.

For these reasons, the SSs recommendations on the inclusion of a caregiver as a coassistant of the hospitalized COVID-19 pediatric patient were essential to be established in the Hospital Infantil de México Federico Gómez (HIMFG), since this is a national reference hospital which, in usual conditions, promotes the permanence of a family member $24 \mathrm{~h}$ a day. However, when implementing these practices, certain limitations arose that led to guideline adjustments. Therefore, we consider that their recognition is of great importance for future implementations in other hospitals.

\section{Experience and adaptation of the guidelines in the HIMFG}

At the pandemic onset, HIMFG became a COVID-19 pediatric hospital in Mexico City (CDMX). During these months, managers and the health-care team were involved in the hospital's operation and logistics changes, adapting specific areas for regular and COVID19 patients. When the implementation of the guidelines began, the first COVID-19 area was insufficient to admit patients together with their caregivers since the flow of patients was more significant than expected, for which it was decided to adjust a larger area for this purpose. Isolated spaces were set up in which it was possible to keep caregivers for a more extended period and more safely, with visiting hours according to the age range and particular needs of each patient (hearing loss, 
developmental delay, and physical or cognitive disability). Consequently, every patient could be accompanied for at least part of the day. Feedback sessions were also held with health-care personnel to address specific aspects, such as the advantages observed in having a family member with the patient, which implied less contact with excretions, mouth and nose secretions, a decrease in accidents such as an intravenous infusion or catheter removal, and stress reduction of patients, families, and health-care personnel.

Based on the conditions marked by the pandemic evolution and the number of admitted patients, these guidelines' initial operation and regulations were modified to extend caregivers' length of stay.

Two guidelines were designed: an extensive one for hospital staff and an abbreviated one for family members of hospitalized patients, highlighting the role of the caregiver (the tasks that must be performed for nursing support and the COVID area rules), and the adherence to hygiene and safety rules. Visits in the Pediatric Intensive Care Unit (PICU) would be restricted for conscious patients under the same selection criteria, schedules, and training.

\section{Adaptation of hospital areas}

\section{Area of suspicion}

A new area in the emergency service was prepared for patients presenting respiratory symptoms or fever or previous contact with a COVID-19 positive patient. Patients undergo tests and remain with the caregiver while waiting for results.

\section{COVID area}

A temporary room in the emergency service was prepared for patients with confirmed COVID-19 diagnosis and family members during visiting hours.

\section{Pediatric intensive care unit}

The pediatric intensive care unit was prepared for critically ill COVID-19 patients requiring assisted ventilation. Family visits were allowed only for awake patients on a fixed schedule.

\section{Admission of patients to the COVID area}

The need for different routes for the diagnosis and isolation of patients who tested positive was examined:
- Outpatients who attend triage on suspicion of the disease

- Patients who attend the emergency room for any complication

- Patients admitted directly to the PICU

- Patients at the hospital due to a baseline diagnosis or a surgical procedure.

\section{Route of admission and stay for family members of COVID-19 patients}

- Public relations department is in charge of receiving the relatives of COVID-19 patients to ensure identification and access permission consistent with the epidemiology department's assessment. The same entrance and exit door was adapted to avoid the family member's displacement around different hospital areas.

- Health checkpoint, in which the body temperature of the relatives is measured. Access is denied if any person has a body temperature $>38^{\circ} \mathrm{C}$.

- Family members must wear masks and wait in the designated area until instructed to wear personal protective equipment (PPE), supervised by a nurse.

- If the visit has to be interrupted by some procedure or any modification in the visiting hours, the family member must leave the area. Subsequently, the family member will be informed by phone of the steps to be followed.

- An area outside where relatives of suspected patients can stay was adapted. In this area, psychological care is provided to relatives when the patient is confirmed as a case of COVID-19.

- A plastic toy is allowed for each patient, which is disinfected every $3 \mathrm{~h}$ and remains in the area on discharge.

We have two cell phones to contact family members and patients $>5$ years old hospitalized within the COVID area. We also have two tablets (which were introduced with safety and hygiene measures) in the PICU. These devices were configured to function as communication bridges between patients and their caregivers but not as free access to the network.

- Psychology and nursing capsules on PPE training, nursing assistance, and care within the COVID area were recorded for family members.

\section{Recommendations from the Epidemiology Department}

Verifying the caregivers' medical status: if they have symptoms, they are sent home, and another caregiver 


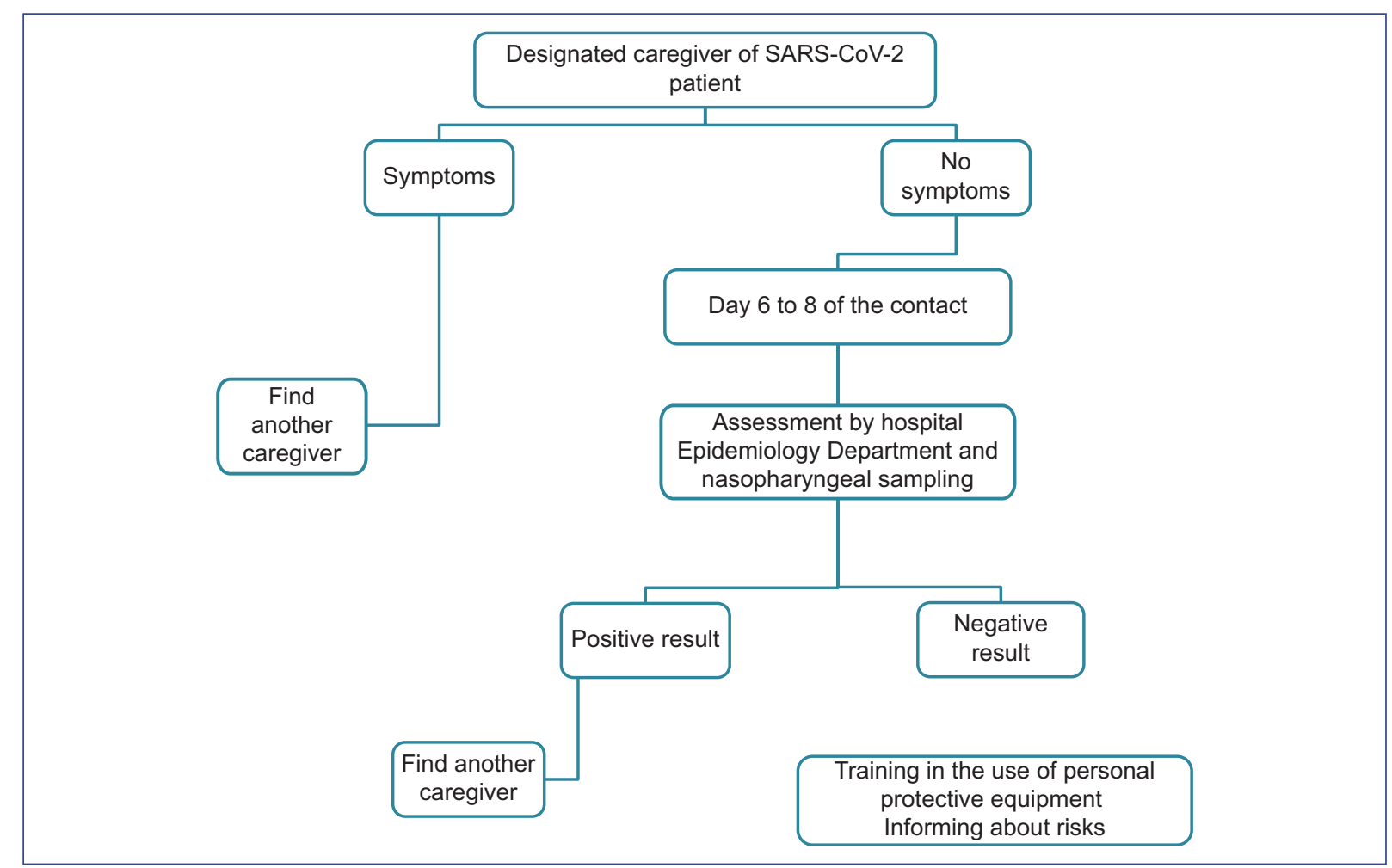

Figure 2. Flowchart adapted at the Hospital Infantil de México Federico Gómez. SARS-CoV-2: severe acute respiratory syndrome coronavirus 2.

is sought. If they have no symptoms and 6 days of contact with a COVID-19-positive patient have passed, they are sent for a consultation with the hospital Epidemiology Department (Fig. 2).

Initially, the proposal was to test all caregivers for severe acute respiratory syndrome COV 2 (SARSCoV-2). However, given the high frequency of false-negative results in the early days of infection and false positives after day 8 of infection (which do not necessarily imply that the virus is present), it was decided to test only those between days 6 and 8 of contact, monitoring daily symptoms, and the wearing of three-layer masks and gowns at all times.

Furthermore, a place for the caregivers' rest and personal hygiene was accustomed and adapted.

A schedule was also designed to assess caregivers. An infectious disease specialist, or epidemiologist, carried out the assessment. The evaluation consisted of recording vital signs, history and treatment of illnesses, and general data on the family member. It was also asked about the caregiver's last contact with any person being tested for or with confirmed SARS-CoV-2 infection.
If the caregiver met the definition of contact (physical contact or contact with a COVID-19 patient's secretions with no PPE) within the previous 6-8 days, a pharyngeal and nasopharyngeal sample was collected for SARS-CoV-2 tests. RT-PCR (real-time reverse transcription-polymerase chain reaction) test results are considered positive when the cycle threshold $(\mathrm{Ct})<24$ and negative when $\mathrm{Ct}>24$.

If the test is positive, another family member should be sought. If it is negative, then the caregiver is allowed to accompany the patient. In addition, the caregiver is informed of the risks and the importance of the PPE use, following indications and prevention measures. Epidemiology results and evaluation are explained at the moment and documented in a note (Fig. 3).

\section{Adjustment of psychological intervention}

1. A coordination of psychological care was established to perform a census of COVID-19 patients.

2. The psychologists evaluated and followed up with both the patient and the family member for the following purposes:

- To intervene in crises when necessary. 


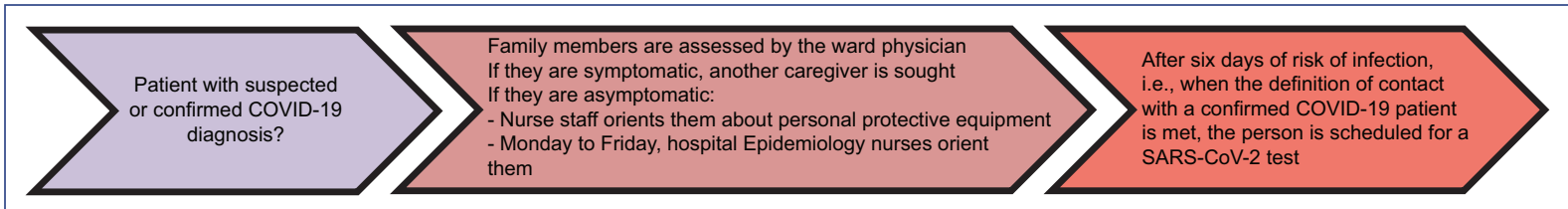

Figure 3. Diagram adapted at the Hospital Infantil de México Federico Gómez. COVID-19: coronavirus disease 2019; SARS-CoV-2: severe acute respiratory syndrome coronavirus 2.

- To investigate the COVID-19 history of the caregiver and close family.

- To clinically evaluate the emotional responses of the family member and the patient regarding diagnosis and hospitalization.

- To explore the family member's psychological characteristics and determine their hospital stay (adherence or conflict behaviors).

- To establish a diagnosis of family structure.

- To explore social support resources.

- To guide on expected responses of children during hospitalization and strategies of emotional containment and regulation.

- To assess the understanding of the medical information received.

- To verify the caregiver's proper training and understanding to enter the area, their role as an assistant, the regulations, and the importance of adherence.

- To establish a link of effective communication between the family member and healthcare personnel.

- To identify if the caregiver accompanied the patient. If not, the reasons why not.

\section{During hospital stay}

- To provide continuous evaluation of the evolution of the emotional state of the patient and caregiver.

- To reinforce adherence to regulations, understanding of indications and medical information, emotional regulation, assertive communication, and problem-solving.

- To analyze the caregivers' and patients' perception of the quality of attention and provide feedback to the team.

\section{During the follow-up}

- To call the caregiver before, during, and after implementing the guidelines and systematically assess the guidelines application's impact through standardized instruments.

- On discharge, contact is maintained by telephone with the caregiver-patient binomial to detect acute stress symptoms and prevent post-traumatic stress disorders, depression, and anxiety. Readaptation and maintenance of health care are addressed.

\section{Experience and limitations}

This unprecedented experience has had different aspects to which the entire team has adjusted to provide optimal patient care. The priority was to attend and solve the situations that arose as a team.

Establishing clear processes and roles for the team and the different areas involved were fundamental to implementing the guideline and improving the service's organization.

- Telephone attention is an emergency option that is not sufficient to support patients, companions, and staff. Consequently, the second level of intervention was implemented through face-to-face psychological care.

- The following limitations on identifying the ideal caregiver and keeping caregivers inside the COVID area were faced.

- Family member's health status was not always optimal.

- The fear of contagion or the protective conditions in the COVID area can be so uncomfortable that caregivers prefer not to be inside, generating feelings of ambivalence and guilt.

- Some teens are afraid of infecting their family members, so they choose to be left alone.

The health-care staff felt that including a caregiver would represent more significant difficulties, risk of infection, questioning, and obstacles. Thus, work was done to raise awareness of the benefit of including the family member as an assistant (including being in charge of activities such as feeding, changing the diaper, and cleaning the patient, among others). At the 
same time, the caregiver was trained on the importance of being a supporter within the area.

- In the case of families with a history of losing relatives because of COVID-19, the binomial's affective state became more complicated, increasing the fear of complications. In such cases, after a thorough investigation of their emotional state, considerations were established that allowed the caregiver to accompany the patient longer than the established schedule and received a closer psychological follow-up.

\section{Discussion}

During the implementation of the guidelines, the authorities collaborated with the COVID team to carry out adaptations and changes according to patient flow, hospital infrastructure, and human and material resources. The importance of having transparent processes, functions, and roles by informing the entire health-care team verbally and in writing was emphasized to standardize information and thus improve the quality of care. The authorities' support and the medical, nursing, and administrative staffs were fundamental to establish these measures.

The process's characteristics and complications emphasized the importance of mental health professionals to be integrated into a transdisciplinary model to act as a bridge between the institution, health-care personnel, family, and patient. The family-centered model optimizes care, interpersonal relationships, and the functioning of the team and the institution. In this sense, the essential premise is clear and direct communication, for which members of the mental health field should be trained to act as organizers to improve the interaction between the parties involved.

Based on our observations, we suggest that the adaptation to the conditions that each hospital faces is necessary to implement the guidelines. Therefore, it is essential to anticipate, prepare, and adapt to different areas to avoid operational difficulties.

Special situations in specific populations such as newborns, patients with disabilities, or patients with chronic illness should also be considered, as the additional circumstances faced may increase the distress of family members. These situations could increase the pressure and decrease the understanding and assimilation of information.

It was confirmed that the guidelines have to be adapted to each hospital center's resources and needs. Moreover, its implementation should be flexible, adjusting quickly to the situations, but always privileging the bio-psycho-social well-being of patients, their families, and health-care personnel.

This pandemic has shown that the execution of a transdisciplinary effort is essential for the proper development of care programs, especially when it comes to emergencies like the one we are facing, and that this model should operate under normal circumstances.

Experience confirms the importance of considering patients' mental health and psychosocial needs as integral care elements since physical and emotional health are equally significant.

Authorities must be guarantors of the actions presented here to improve the quality and warmth of the attention to children and their caregivers. In addition, attention should be provided without bypassing the health-care team and unconditional respect for their needs and rights, employing the cooperation of all institutional organization areas.

Finally, health-care team members should also be addressed due to the emotional impact they experience in a critical situation. Therefore, it is necessary to sensitize them to seek help when they perceive the first symptoms as a preventive measure to improve their professional performance.

\section{Ethical disclosures}

Protection of human and animal subjects. The authors declare that no experiments were performed on humans or animals for this study.

Confidentiality of data. The authors declare that they have followed the protocols of their work center on patient data publication.

Right to privacy and informed consent. The authors declare that no patient data appear in this article.

\section{Conflicts of interest}

The authors declare no conflicts of interest.

\section{Funding}

None.

\section{References}

1. Dong $Y$, Mo X, Hu Y, Qi X, Jiang F, Jiang Z, et al. Epidemiological characteristics of 2143 pediatric patients with 2019 coronavirus disease in China. Pediatrics. 2020;145:e20200702.

2. Royal College of Paediatrics and Child Health. COVID-19-Isolation Plans for Parent-Child Combinations. Wales: Royal College of Paediatrics and Child Health; 2020. Available from: https://www.rcpch.ac.uk/resources/ covid-19-isolation-plans-parent-child-combinations. 


\section{Luque-Coqui, et al.: Caregiver of the hospitalized COVID-19 pediatric patient}

3. Asociación Española de Pediatría. Manejo del Paciente Pediátrico ante Sospecha de Infección por el Nuevo Coronavirus SARS-CoV-2 en Atención Primaria (COVID-19). Madrid: Asociación Española de Pediatría 2020. Available from: https://www.aepap.org/sites/default/files/noticia/archivos-adjuntos/2020_04_07_covid_ap.pdf.

4. New York-Presbyterian. General Visitation Guidelines. New York: New York-Presbyterian; 2020. Available from: https://www.nyp.org/coronavirus-information/coronavirus-visitor-policy-change-spanish.

5. New York State Opportunity. Department of Health. Health Advisory COVID-19 Guidance for Hospital Operators Regarding Visitation Updated Guidance Regarding Obstetrical and Pediatric Settings. New York: New York State Opportunity; 2020. Available from: https://coronavirus.health ny.gov/system/files/documents/2020/03/doh_covid19_obpedsvisitation 032720.pdf.

6. Sociedad Argentina de Pediatría. Segundo Documento COVID-19: Recomendaciones para la Atención del Paciente Pediátrico con Infección Sars-Cov-19. Buenos Aires: Sociedad Argentina de Pediatría; 2020. Available from: https://www.sap.org.ar/uploads/archivos/general/files_segundo-encuentro-virtual-covid_1585328932.pdf.

7. Secretaría de Salud del Gobierno de México. Recomendaciones para la Integración del Cuidador Primario Como Co-Auxiliar del Equipo de Salud Durante la Estancia Intrahospitalaria del Paciente Pediátrico con COVID-19. Mexico: Secretaría de Salud del Gobierno de México; 2020 Available from: https://coronavirus.gob.mx/wp-content/uploads/2020/06/
Recomendaciones integracion cuidador primario auxiliar equipo salud_estancia_intrahospitalaria_paciente_pediatrico_COVID-19.pdf.

8. MacKean G, Spragins W, L'Heureux L, Popp J, Wilkes C, Lipton H. Advancing family-centred care in child and adolescent mental health: a critical review of the literature. Healthc Q. 2012;15:64-75.

9. Committee on Hospital Care, American Academy of Pediatrics. Family-centered care and the pediatrician's role. Pediatrics. 2003;112:691-7.

10. Fernández-Castillo A, López-Naranjo I. Estrés parental en la hospitalización infantil. Ansiedad Estrés. 2006;12:1-17.

11. Gobierno de España. Manejo Clínico de Pacientes con Enfermedad por el Nuevo Coronavirus (COVID-19). Madrid: Ministerio de Sanidad, Consumo y Bienestar Social de España; 2020.

12. Urdiales LD. Aspectos Psicológicos del Niño Hospitalizado [Dissertation]. Valladolid: Universidad de Valladolid; 2017.

13. Hernández $E$, Rabadán JA. La hospitalización: un paréntesis en la vida del niño. Atención educativa en población infantil hospitalizada. Persp Educ. 2013;52:167-81.

14. Aarthun A, Akerjordet K. Parent participation in decision-making in health-care services for children: an integrative review. J Nurs Manag. 2014;22:177-91.

15. Astudillo AA, Martínez MA, Muñoz BC, Pacheco LM, Sepúlveda GA Acompañamiento familiar en la hospitalización del usuario pediátrico de 6 a 12 años. Cienc Enferm. 2012;18:67-75. 